
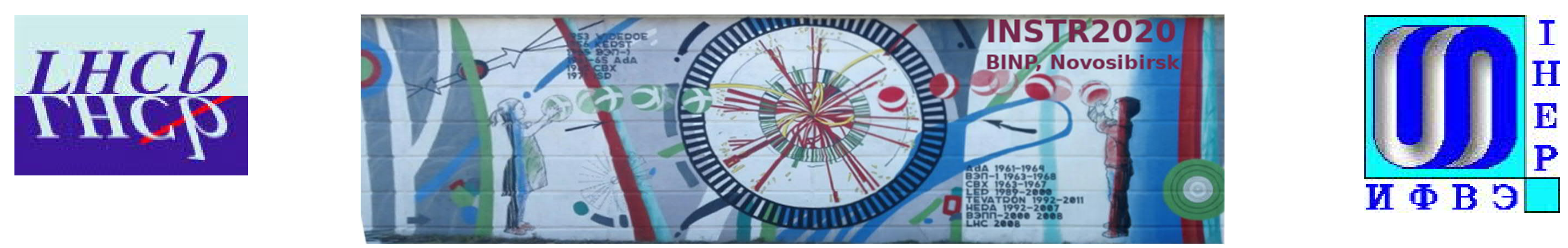

\author{
The Phase 2 Upgrade \\ of the LHCb Calorimeter system.
}

Yu. Guz (IHEP Protvino)

on behalf of the LHCb collaboration 


\section{The LHCb experiment}

A single arm forward spectrometer at LHC.

Flavor physics, CP violation, hadron spectroscopy.

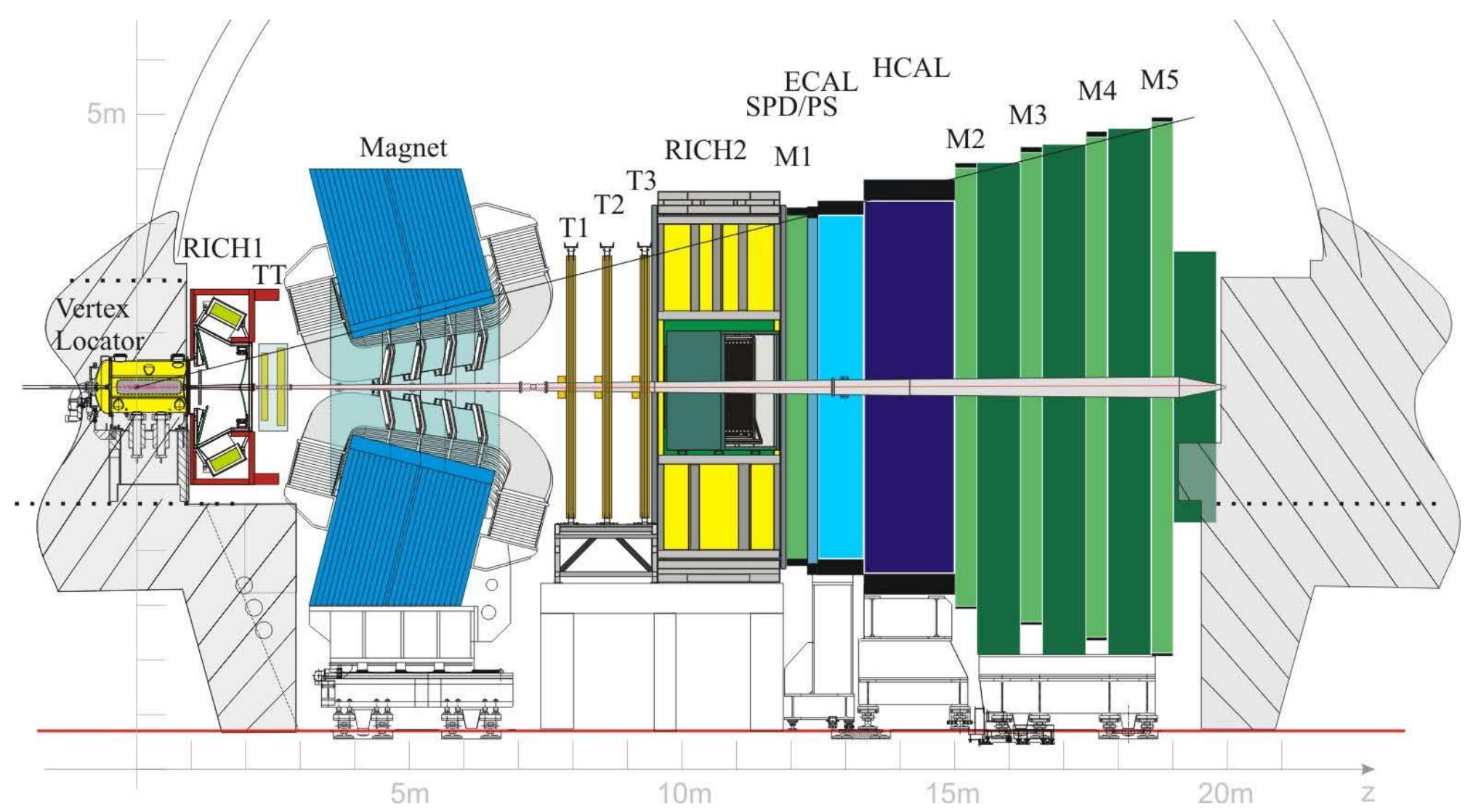




\section{The LHCb Calorimetry System of Run I and Run II}

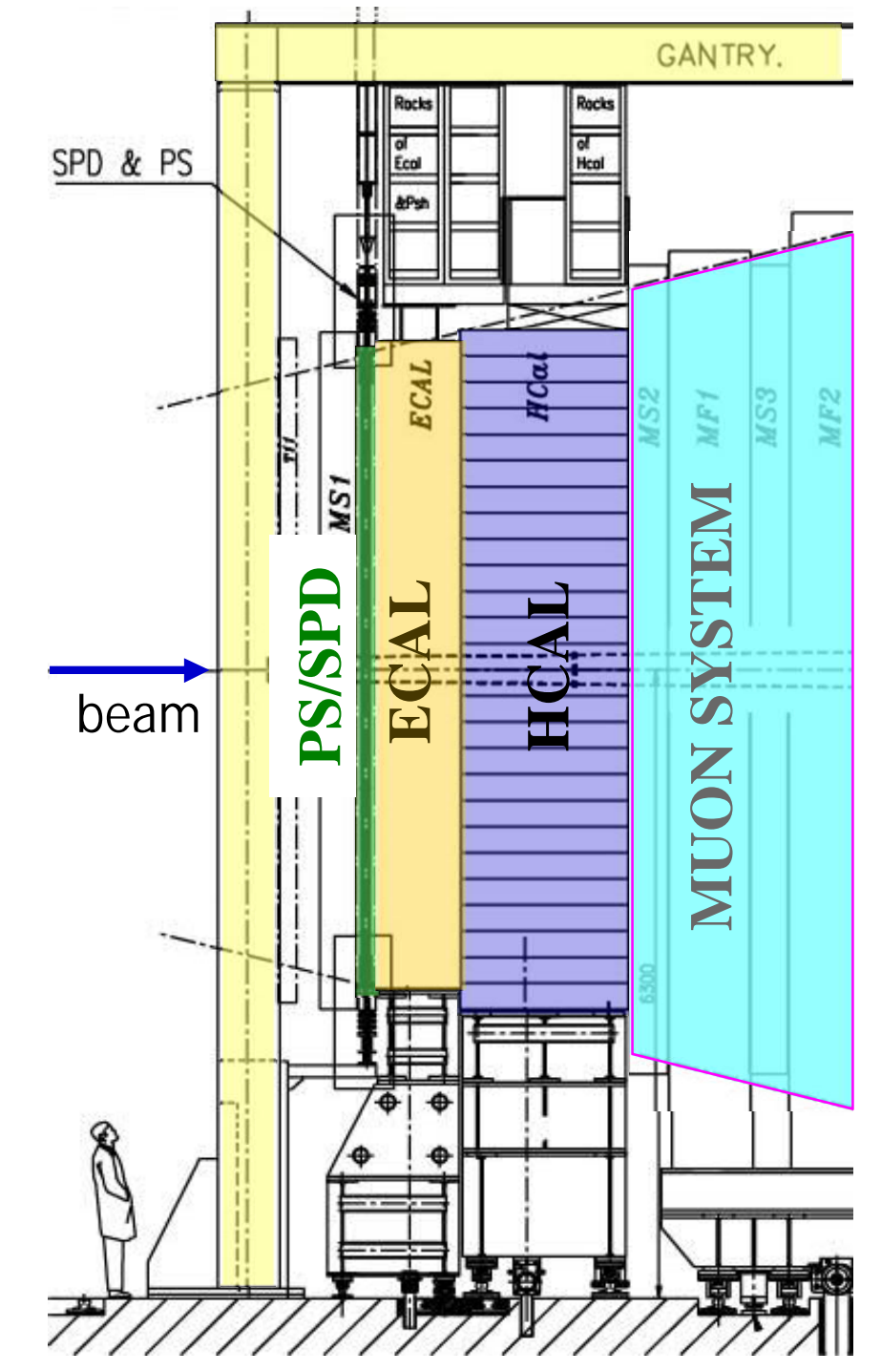

solid angle coverage: $300 \times 250 \mathrm{mrad}$

$>$ distance from IP: $\sim 12.5 \mathrm{~m}$

$>$ four subdetectors: SPD,PS,ECAL,HCAL

$>$ based on scint./WLS technique, light readout with PM T

$>$ provides:

- L0 trigger on high $p_{\top} e^{ \pm}, \pi^{0}, \nu$, hadron

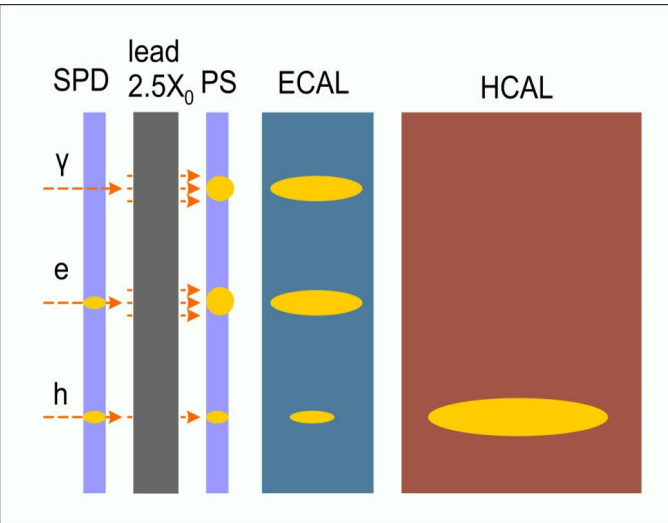

- precise energy measurement of $\mathrm{e}^{ \pm}$ and $\gamma$

- particle identification: $\mathrm{e}^{ \pm} / \mathrm{\gamma} /$ hadron; contributes to Muon ID (HCAL). 


\section{The LHCb ECAL}

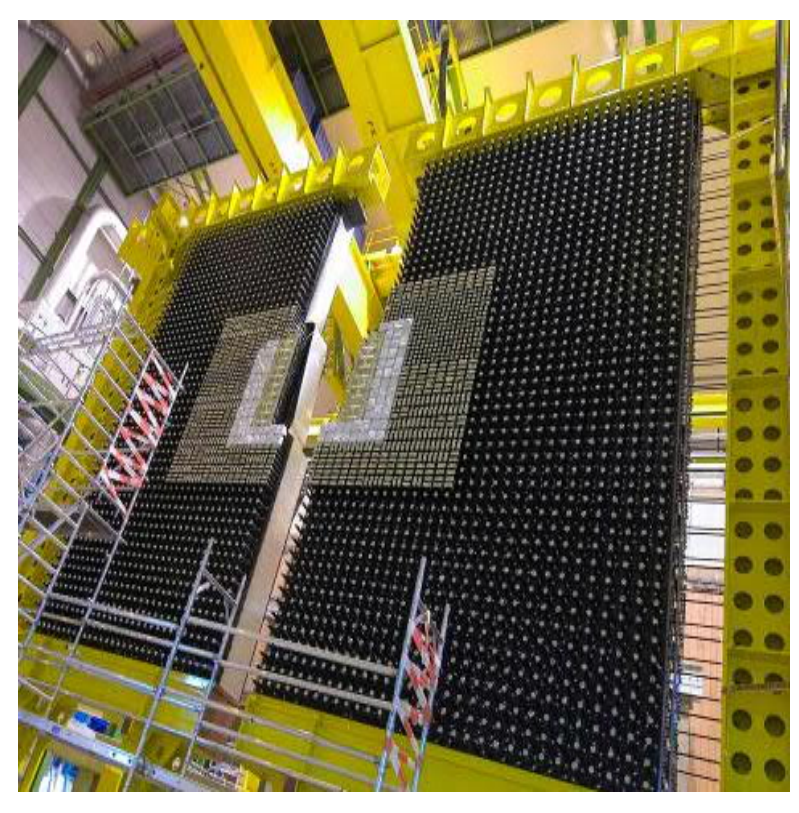

Average performance figures from beam test (there is slight difference between zones):

Light yield: $\sim 3000$ ph.el. / GeV

Energy resolution: $\frac{\sigma_{E}}{E}=\frac{(8 \div 10) \%}{\sqrt{E(G e V)}} \oplus 0.9 \%$

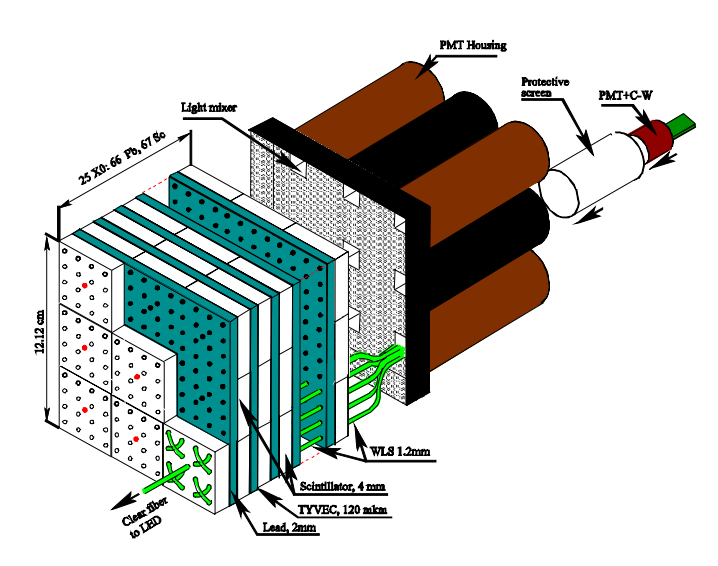

Shashlik technology
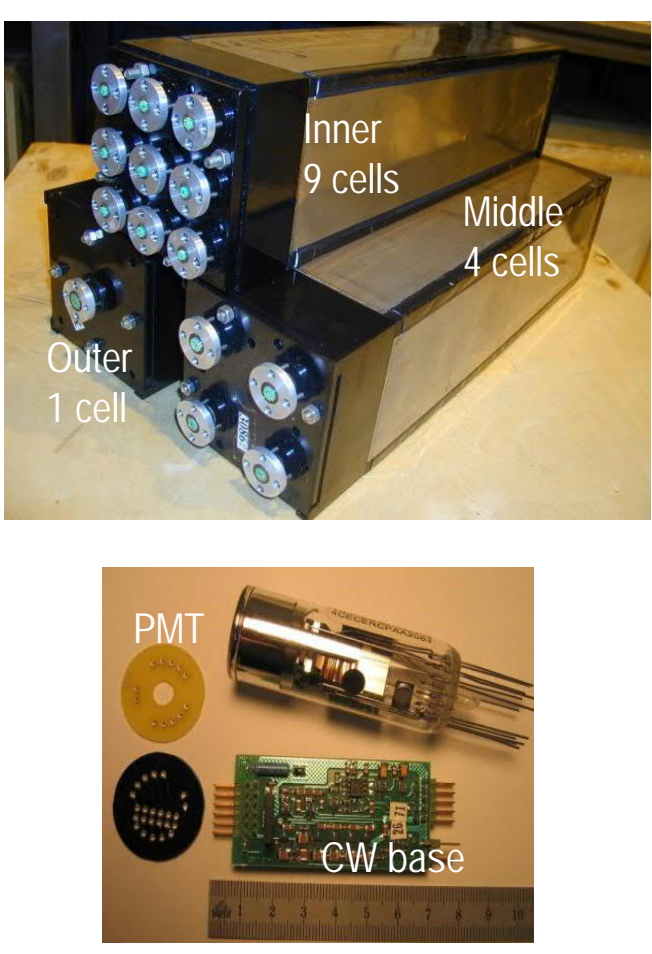

- $4 \mathrm{~mm}$ thick scintillator tiles and $2 \mathrm{~mm}$ thick lead plates, $\sim 25 \mathrm{X}_{0}\left(1.1 \lambda_{1}\right)$; M oliere radius $\sim 36 \mathrm{~mm}$;

- modules $121.2 \times 121.2$ mm², $66 \mathrm{~Pb}+67$ scintillator tiles;

- Segmentation: 3 zones $\rightarrow 3$ module types, Inner (9 cells per module), Middle (4), Outer (1). Total of 3312 modules, 6016 cells, $(7.7 \times 6.3) \mathrm{m}^{2}, \sim 100$ tons.

- Light readout: PM T R-7899-20, HAM AM ATSU. HV supply: individual Cockcroft-Walton circuit at each PM T.
The Phase 2 Upgrade of the LHCb Calorimeter system

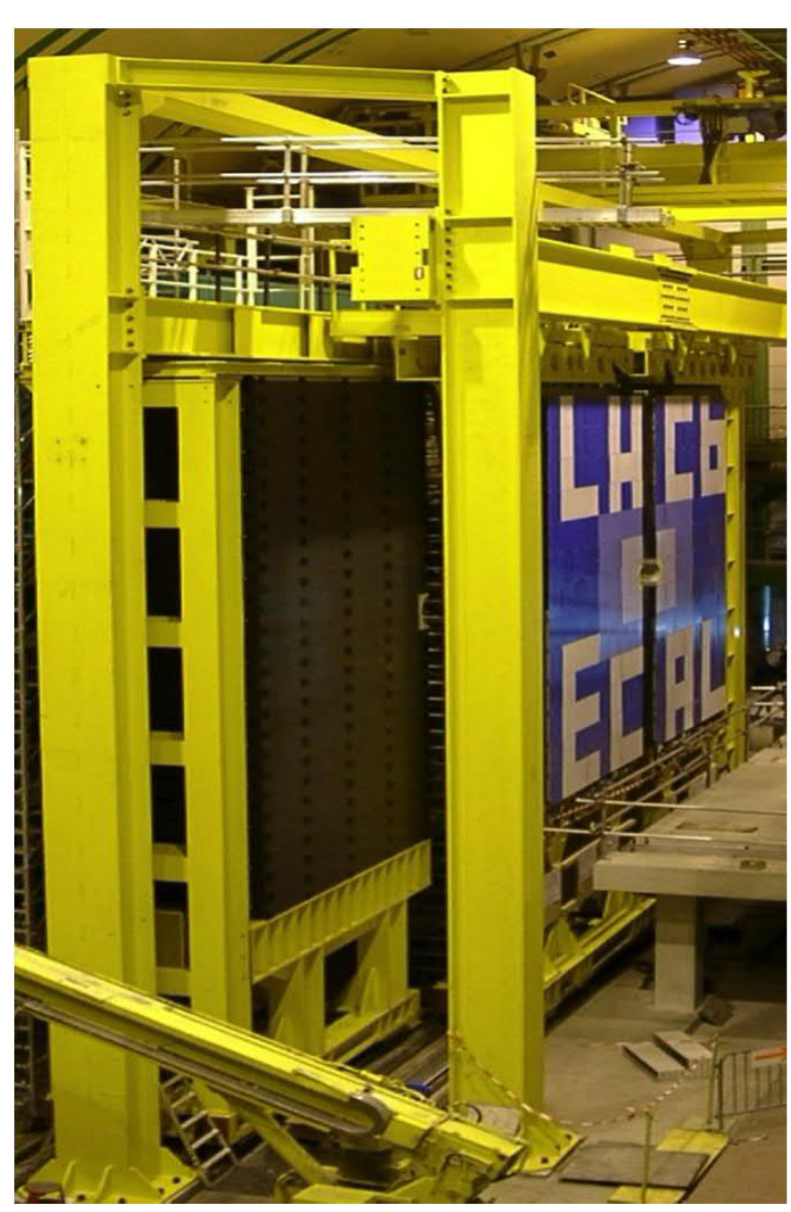

Yu. Guz 


\section{LHCb Upgrade 1}

Luminosity: $4 \cdot 1032 \rightarrow 2 \cdot 1033 \mathrm{~cm}-2 \mathrm{~s}-1$

Detector upgrade to $40 \mathrm{MHz}$ readout

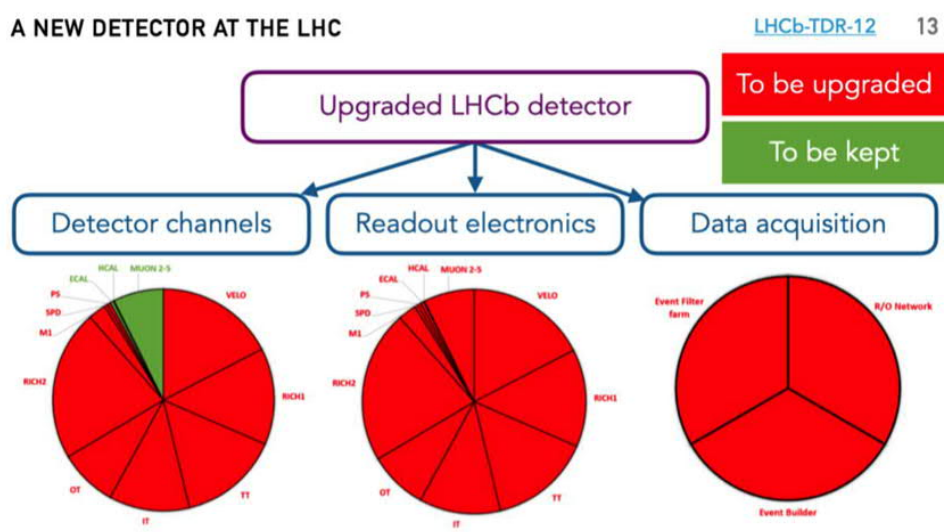

- Less than $10 \%$ of the detector will be kept

- $100 \%$ of the readout electronics will be replaced

- NEW data acquisition system and data center

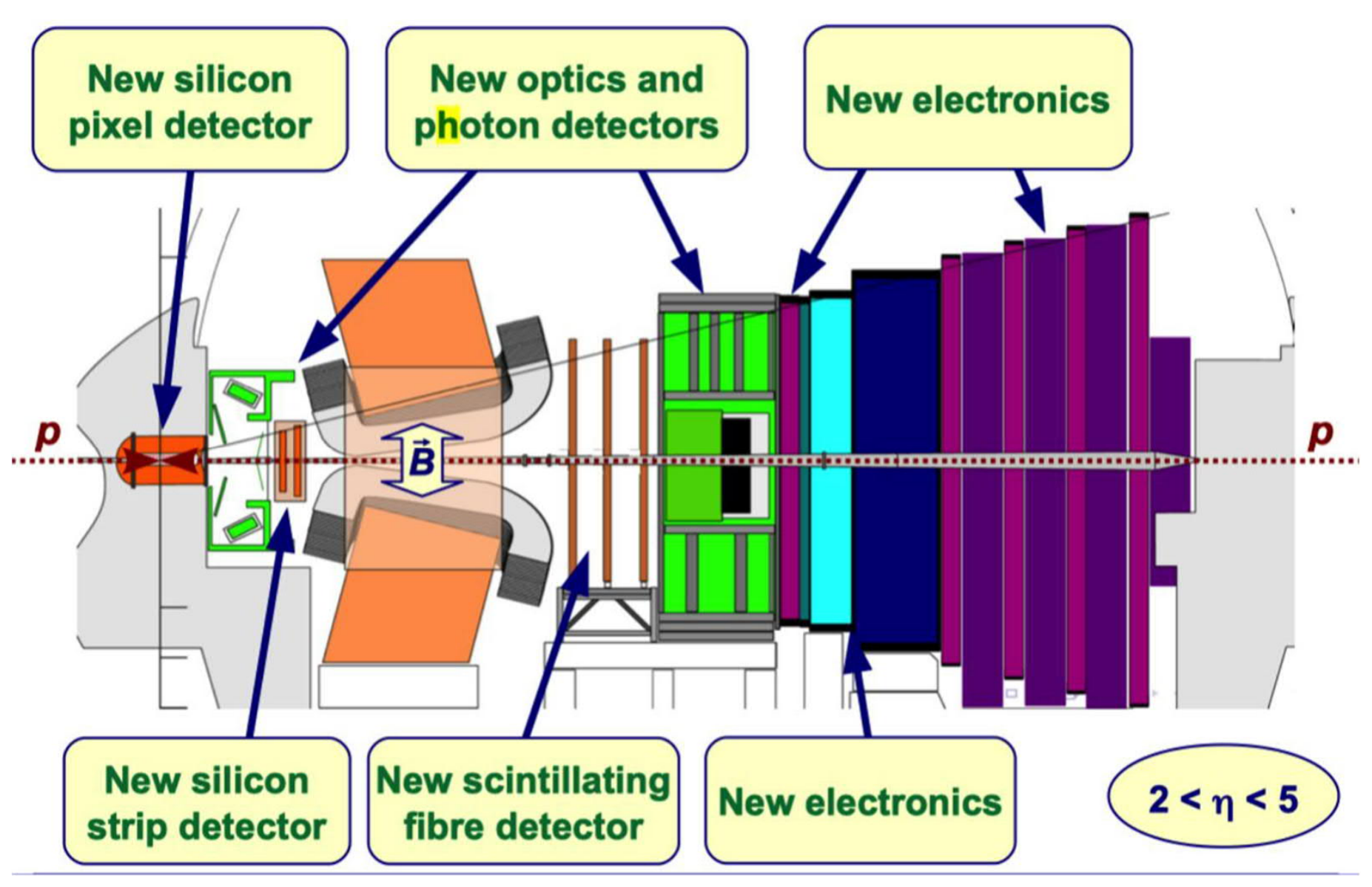




\section{LHCb CALO Upgrade - phase 1 (ongoing)}

Luminosity $2 \cdot 10^{33} \mathrm{~cm}^{-2} \mathrm{~s}^{-1}$ ( $5.5 p p$ interactions per event):

$>$ PS and SPD are removed: no need for particle ID in L0

$>$ no change in the present ECAL and HCAL

\section{For Run 3:}

$>$ the frontend electronics is being replaced to new one, compatible with the new DAQ \& Trigger

$>$ The PMT gain will be reduced by factor of $\sim 5$, to reduce PMT degradation

- PMT linearity: OK within required dynamic range

$>$ to compensate, the FE gain will be increased $x 5$

$>$ new low noise ASIC (ICECAL)

$>$ detector maintenance will follow radiation degradation of detector components:

- regular replacement of degraded parts (PMTs / Cockcroft-Walton HV boards)

- LS3: replacement of ECAL Inner modules
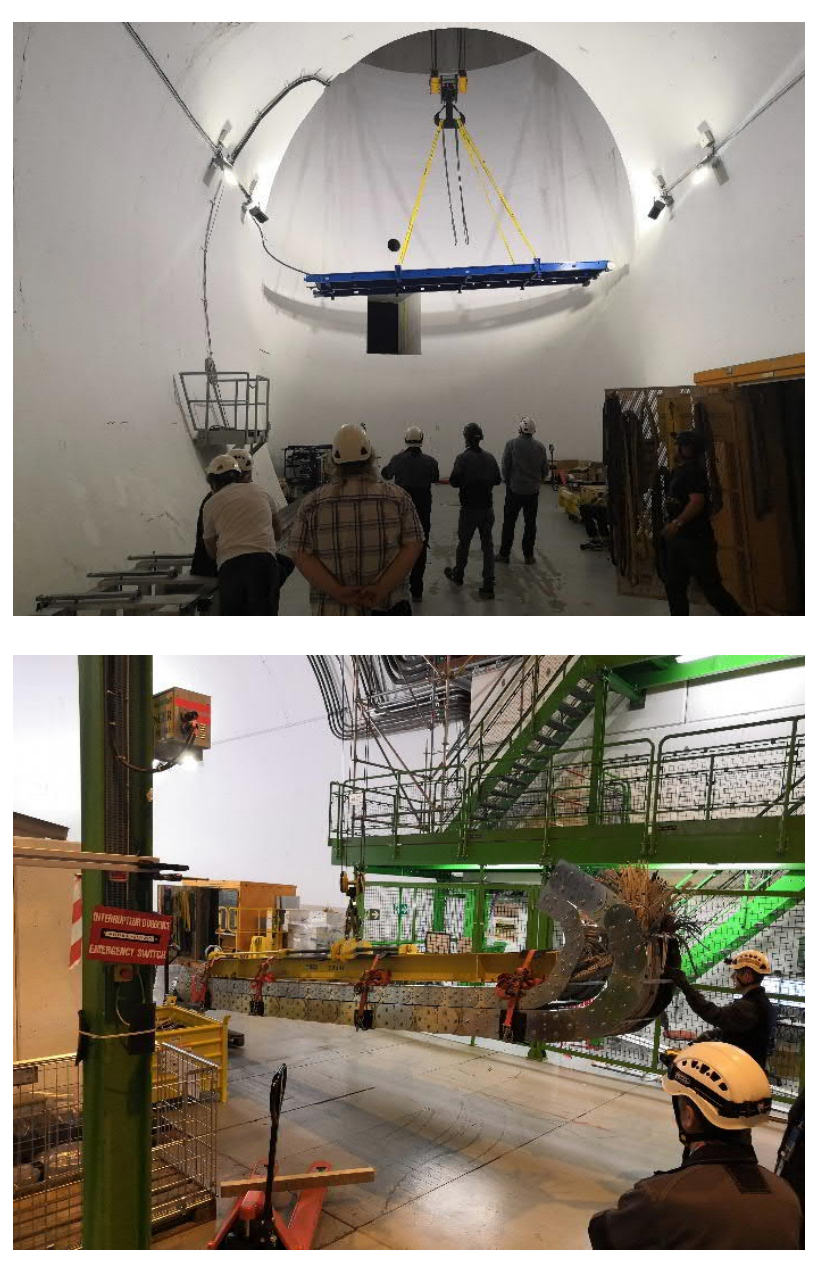


\section{LHCb - the long term roadmap}

\begin{tabular}{|c|c|c|c|c|c|c|c|c|c|c|c|c|c|c|c|c|c|}
\hline 2019 & 2020 & 2021 & 2022 & 2023 & 2024 & 2025 & 2026 & 2027 & 2028 & 2029 & 2030 & 2031 & 2032 & 2033 & 2034 & 2035 & 2036 \\
\hline \multicolumn{2}{|c|}{$\begin{array}{l}\text { Long Shutdown } 2 \text { (IS2) } \\
\end{array}$} & & & flamen & & \multicolumn{2}{|c|}{$\begin{array}{l}\text { Long Shutdown } 3 \text { (LS3) } \\
\end{array}$} & & Run 4 & & & is & & Run 5 & & Ls5 & \\
\hline \multicolumn{2}{|c|}{$\begin{array}{l}\text { LHCb Upgrade I } \\
40 \mathrm{M} \mathrm{Hz} \text { readout } \\
\text { new detectors } \\
\text { new electronics }\end{array}$} & & $\begin{array}{r}\mathrm{P} \\
2 \cdot 10\end{array}$ & $\begin{array}{l}n 3 \\
\mathrm{~cm}^{-2} \mathrm{~s}^{-1}\end{array}$ & & \multicolumn{2}{|c|}{$\begin{array}{l}\text { Consolidation } \\
\& \text { Maintenance }\end{array}$} & & \multicolumn{3}{|c|}{$\begin{array}{c}\text { Run } 4 \\
2 \cdot 10^{33} \mathrm{~cm}^{-2} \mathrm{~s}^{-1} \\
\quad \rightarrow 50 \mathrm{fb}^{-1}\end{array}$} & $\begin{array}{l}\text { LHCb } \\
\text { Upgrade II }\end{array}$ & \multicolumn{4}{|c|}{$\begin{array}{c}\operatorname{Run} 5,6 \\
2 \cdot 10^{34} \mathrm{~cm}^{-2} \mathrm{~s}^{-1} \\
\quad \rightarrow 50 \mathrm{fb}^{-1}\end{array}$} & \\
\hline
\end{tabular}

\section{Upgrade 2:}

- luminosity up to $2 \cdot 10^{34} \mathrm{~cm}^{-2} \mathrm{~s}^{-1}(\sim 55 p p$ interactions per event)

- $\sim 300 \mathrm{fb}^{-1}$ will be collected

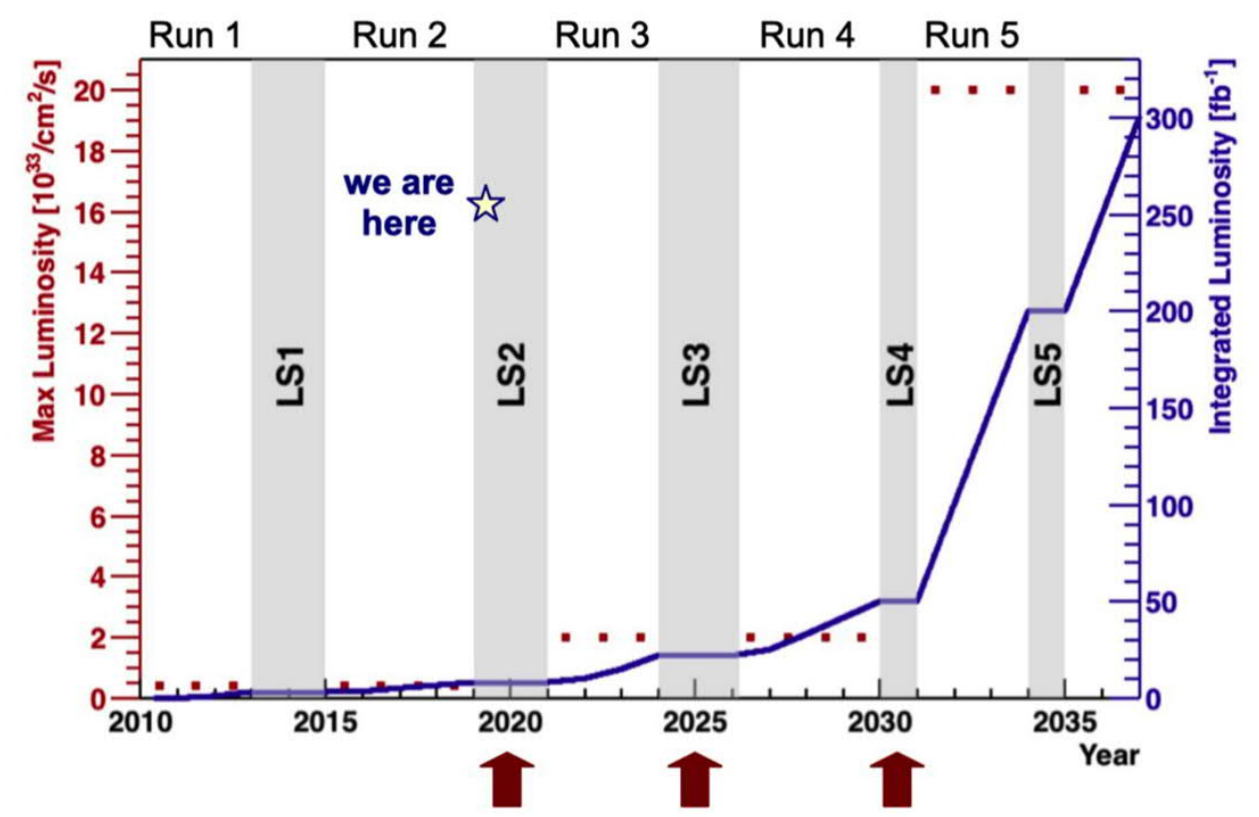




\section{LHCb - the long term roadmap}

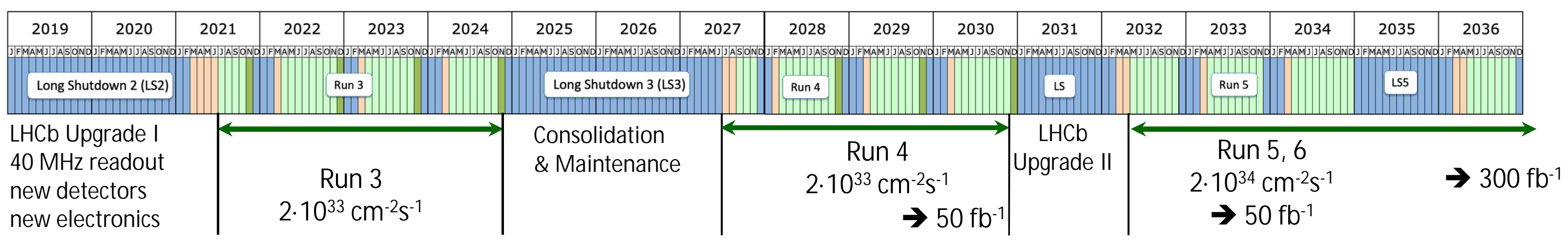

ECAL in LS3 (2025-2027):

- replace modules around the beam pipe ( 32 modules), to improve performance for Run 4

ECAL in LS4 (2031-2032):

- rebuild ECAL for maximum performance at $\mathrm{L}=2 \cdot 10^{34} \mathrm{~cm}^{-2} \mathrm{~s}^{-1}$

- include time measurements to disentangle multiple interactions in a bunch crossing.

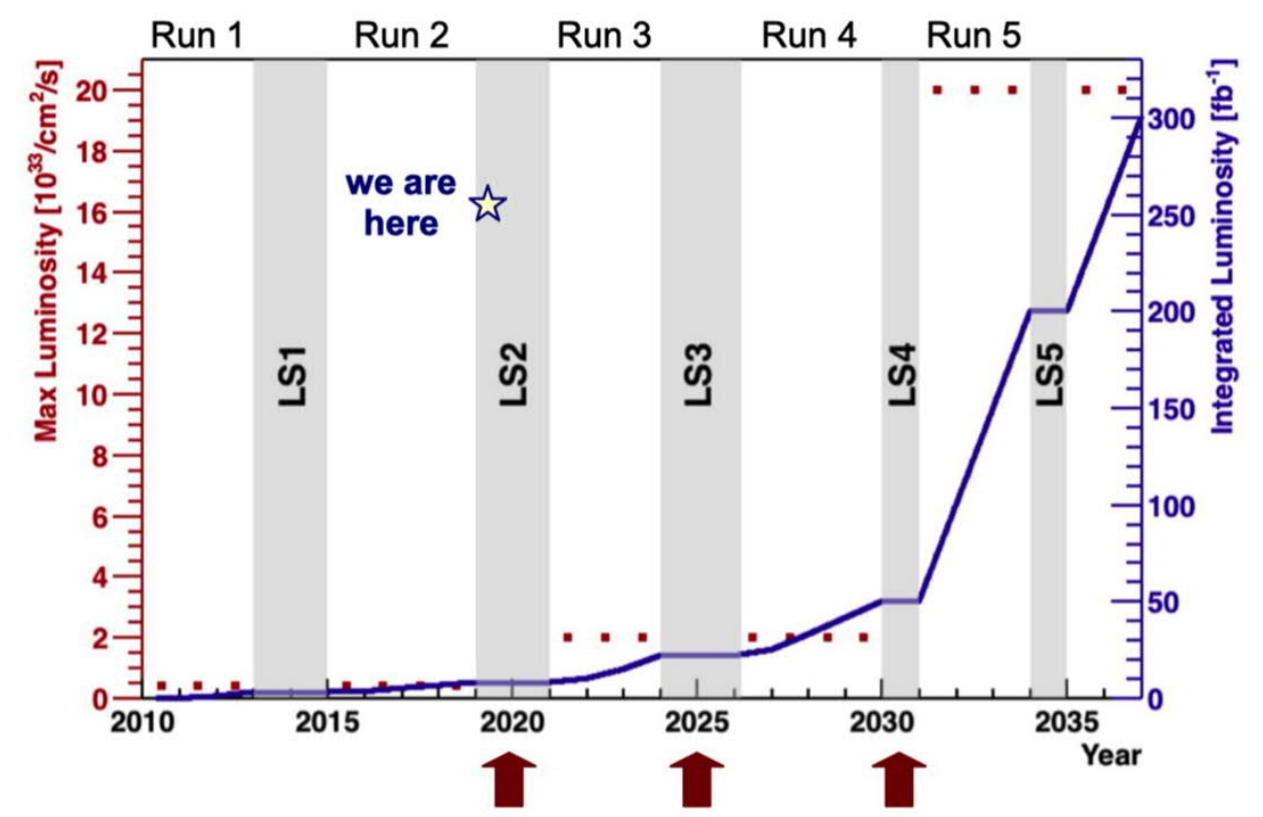




\section{LHCb ECAL Upgrade II - conditions and requirements}

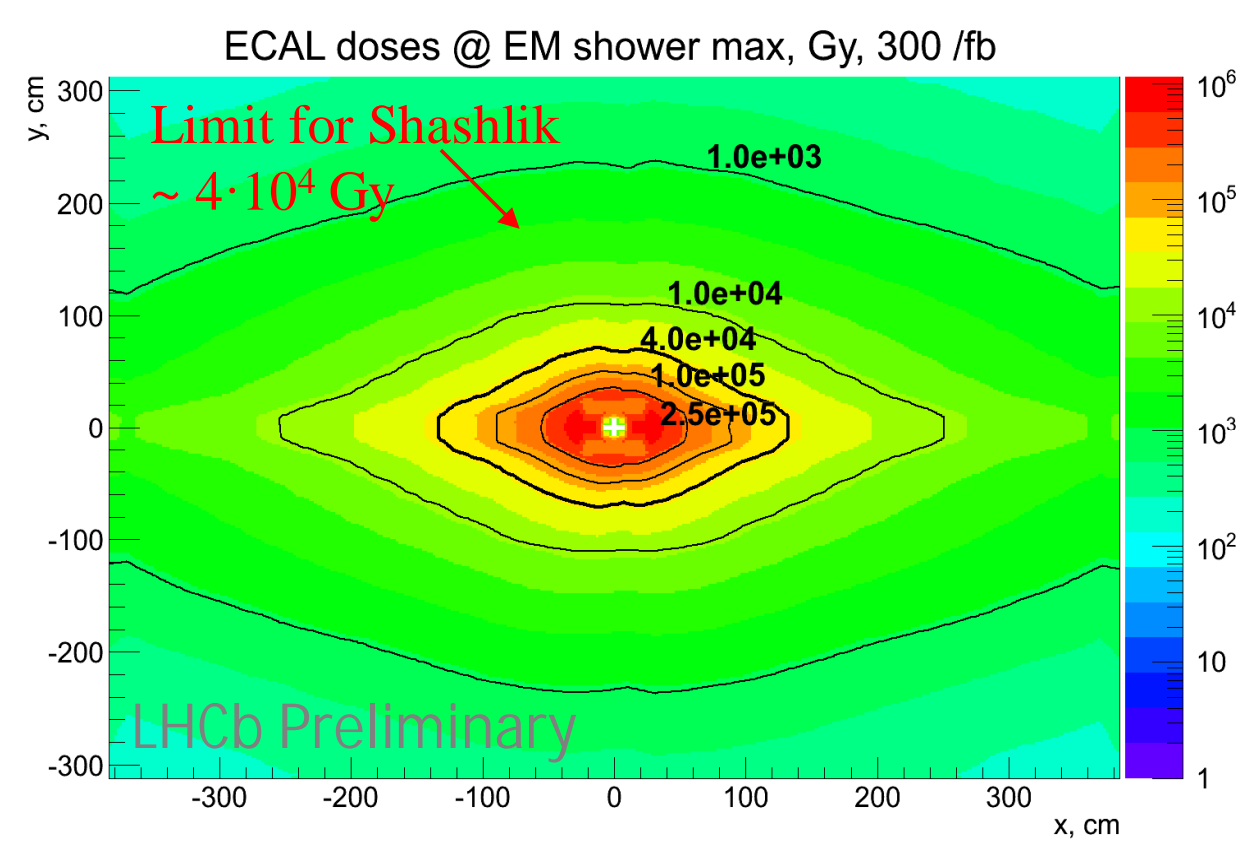

up to 1 MGy in the centre

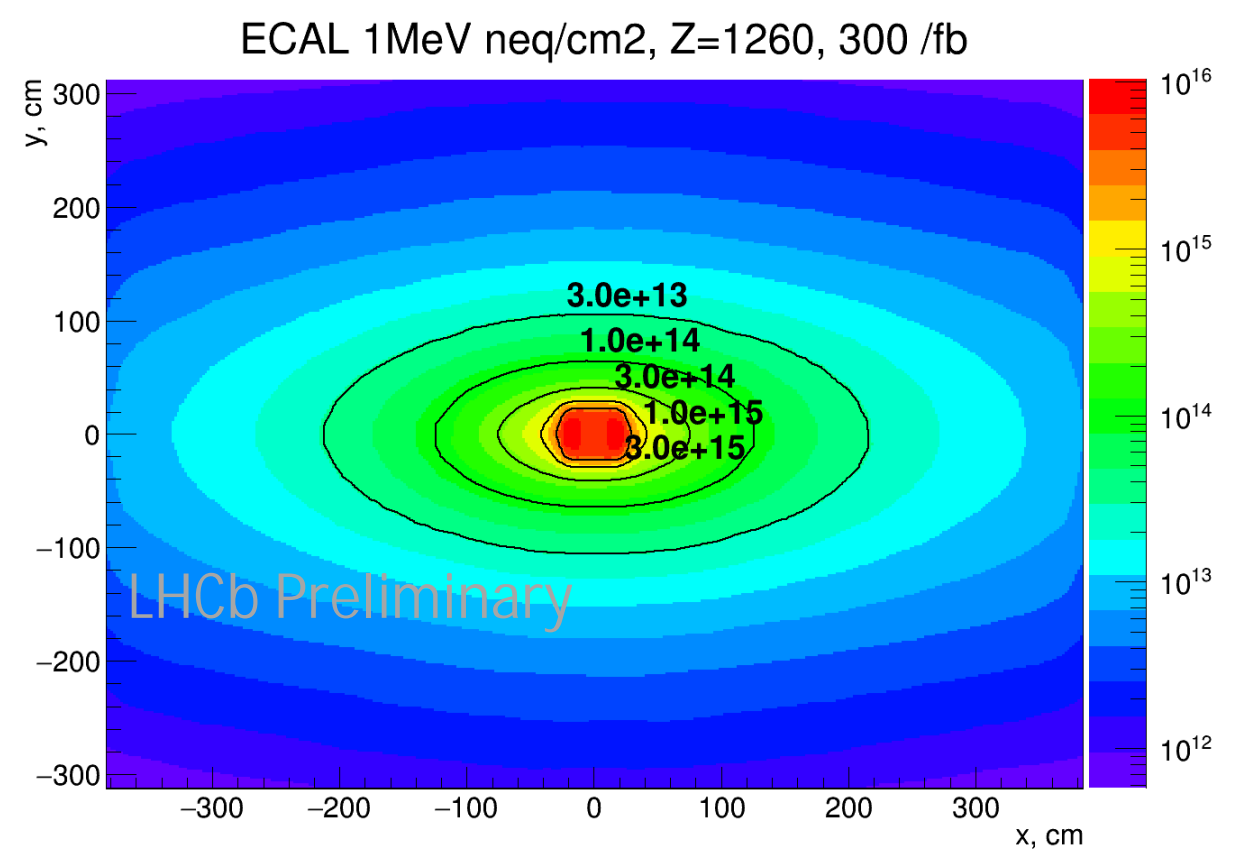

up to $6 \cdot 10^{15} 1 \mathrm{M} \mathrm{eV} \mathrm{neq} / \mathrm{cm}^{2}$ in the centre 


\section{LHCb ECAL Upgrade II - conditions and requirements}

- need at least three areas with different granularities (maybe more)

- two or three different technologies (e.g., for 0-20 krad, 20-200 krad, >200 krad)

- the Central area should sustain radiation doses of up to $\sim 1 \mathrm{M} \mathrm{Gy}$ and neutron fluences of up to 6.1015 $1 \mathrm{M} \mathrm{eV}$ neq $/ \mathrm{cm}^{2}$

- scintillating garnet crystals

- The Outer area: Shashlik is a viable option

- The Middle area - not defined yet (e.g., PWO?)

- requirements for the whole calorimeter:

- fine granularity, which is required to handle increased occupancy

- Molière radius should match the granularity $(\sim 1 \mathrm{~cm}$ at the centre $\rightarrow$ dense absorber!)

- good energy resolution, $\sigma(E) \sim 10 \% / \sqrt{E} \oplus 1 \%$

- ability to measure time with few*10ps precision - for pile-up mitigation. The options are:

- use intrinsic time resolution of the calorimeter modules

- add a dedicated timing layer 


\section{LHCb ECAL Upgrade II - options for the central area}

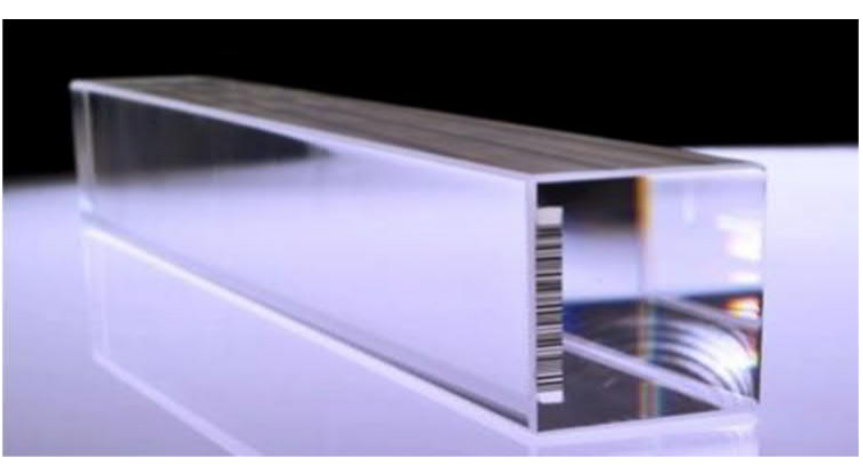

Homogeneous Crystal:

- requires long crystals to contain $25 X_{0}$

- "fixed" M oliere Radius

- very good homogeneity $\rightarrow$ good energy resolution

- requires good radiation hardness (low rad-induced attenuation over the whole length)

- can be mitigated by longitudinal segmentation

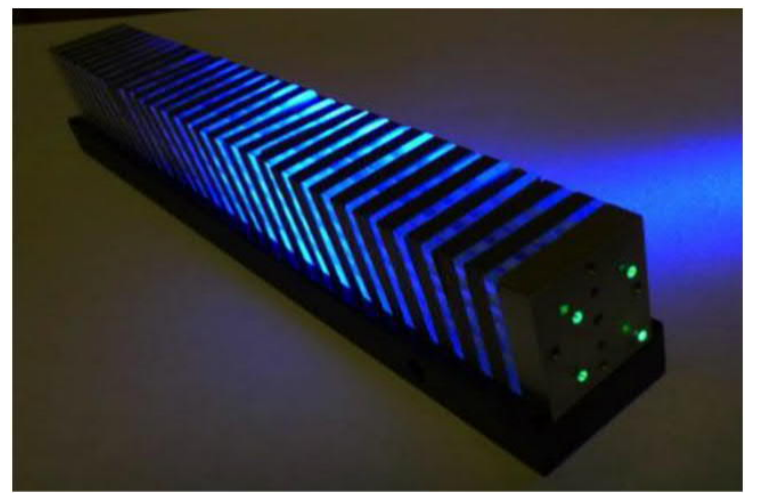

Shashlik type module:

- can be made very compact $\sim 15 \mathrm{~cm}$

- "tunable" Molière radius

- more relaxed requirements to the scintillator rad. hardness (no att. over the cell size)

- but no rad. hard WLS fibers (yet) to transport light!

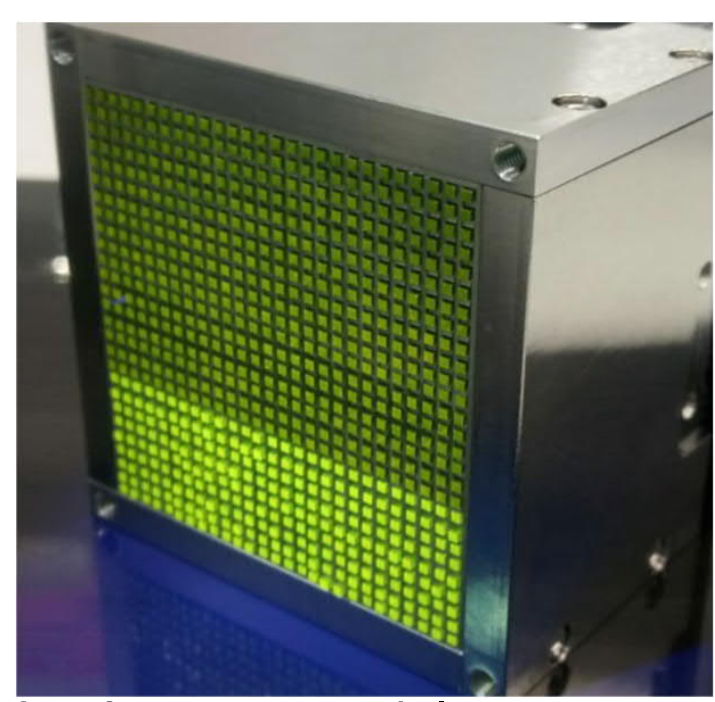

SPACAL type module:

- can be made very compact $\sim 15 \mathrm{~cm}$

- "tunable" Molière radius

- fibers scintillate AND transports light! $\rightarrow$ potentially high photoelectron yield

- worsening energy resolution @ small angles

- radiation hardness requirements are similar to homogeneous crystal, mitigated by

- compact length

- longitudinal segmentation

started R\&D on SPACAL type module, together with Crystal Clear Collaboration

Yu. Guz 


\section{Radiation hard scintillating crystals}

\begin{tabular}{|c|c|c|c|c|}
\hline & $\begin{array}{c}\mathrm{Y}_{3} \mathrm{Al}_{5} \mathrm{O}_{12}: \mathrm{Ce} \\
(\mathrm{YAG})^{*}\end{array}$ & $\begin{array}{l}\mathrm{Lu}_{3} \mathrm{Al}_{5} \mathrm{O}_{12}: \mathrm{Ce} \\
(\mathrm{LuAG})^{*}\end{array}$ & $\begin{array}{c}\mathrm{Gd}_{3} \mathrm{Al}_{2} \mathrm{Ga}_{3} \mathrm{O}_{12}: \mathrm{Ce} \\
(\mathrm{GAGG})^{* *}\end{array}$ & $\begin{array}{l}\mathrm{Lu}_{2} \mathrm{SiO}_{5}: \mathrm{Ce} \\
\text { (LSO) }\end{array}$ \\
\hline density $\left(\mathrm{g} / \mathrm{cm}^{3}\right)$ & 4.57 & 6.73 & 6.63 & 7.4 \\
\hline$x_{0}(\mathrm{~cm})$ & $3.5 \mathrm{~cm}$ & 1.3 & 1.59 & 1.1 \\
\hline Refraction index & 1.83 & 1.84 & 1.85 & 1.82 \\
\hline$\Lambda_{\max }(\mathrm{nm})$ & 550 & 535 & 520 & 420 \\
\hline $\begin{array}{c}\text { LY @ RT } \\
\text { (ph/MeV) }\end{array}$ & 35000 & 25000 & 50000 & 30000 \\
\hline decay time (ns) & $\begin{array}{l}70+\text { slow } \\
\text { component }\end{array}$ & $\begin{array}{l}70 \text { +slow } \\
\text { component }\end{array}$ & $\begin{array}{l}60+\text { slow } \\
\text { component }\end{array}$ & 40 \\
\hline rise time (ps) & $1590-137$ & 923-230 & 497-92 & 59 \\
\hline
\end{tabular}

rise time: S.Gundacker, NIM A 891 (2018) 42-52 


\section{Crystal production}

Grown by Czochralski method
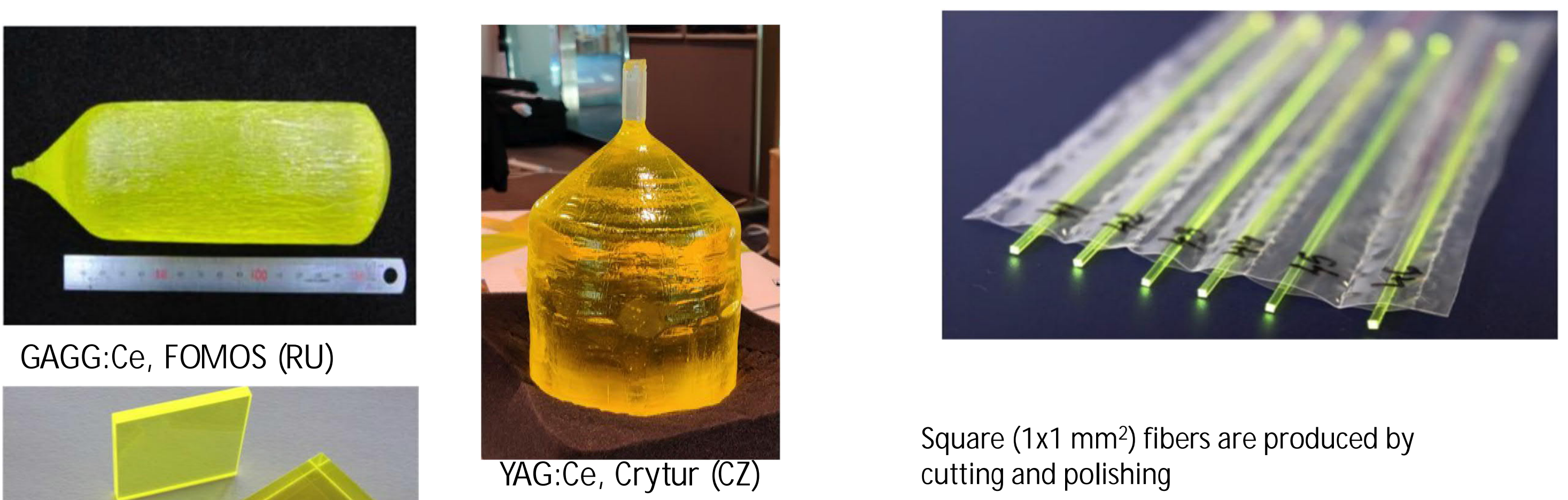

\section{GAGG:Ce, FOMOS (RU)}

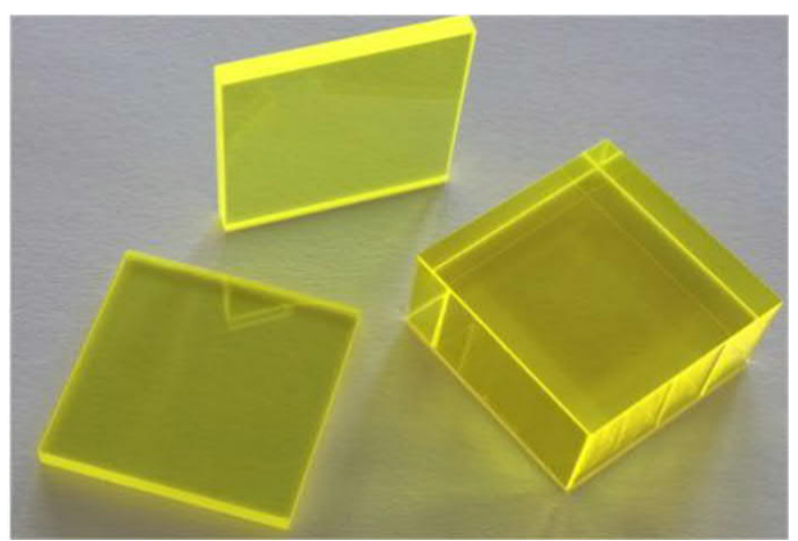

Square $\left(1 \times 1 \mathrm{~mm}^{2}\right)$ fibers are produced by cutting and polishing

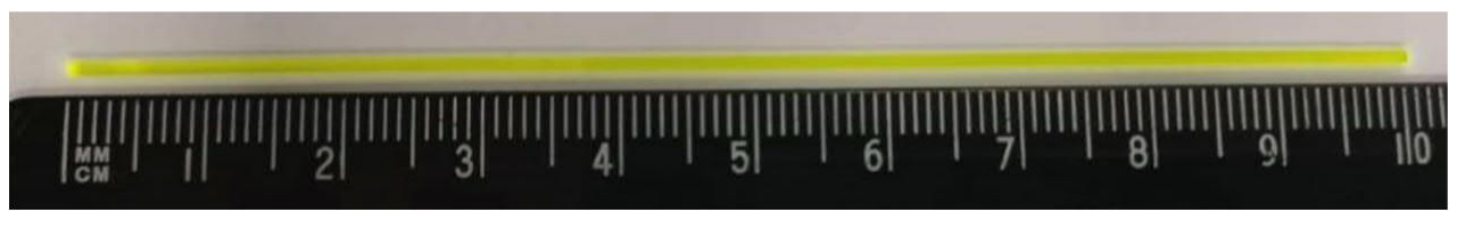




\section{GAGG: radiation hardness}

Sample irradiation, $24 \mathrm{GeV}$ protons $3.1 \cdot 10^{15} \mathbf{p} / \mathrm{cm}^{2}$ (0.91 M gy)

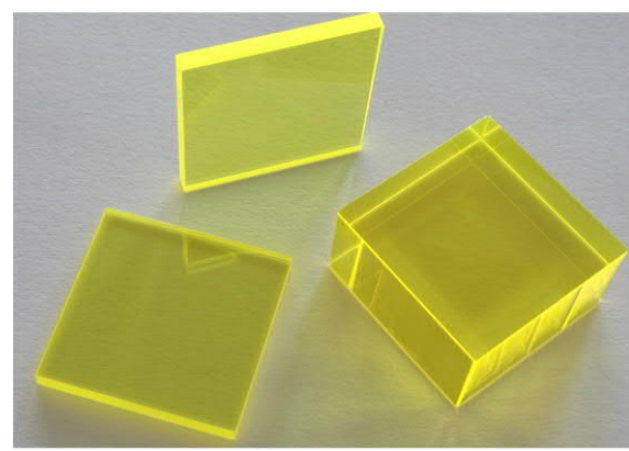

GAGG samples (FOM OS M aterials, M oscow)

GAGG fibers (FOM OS M aterials, M oscow)

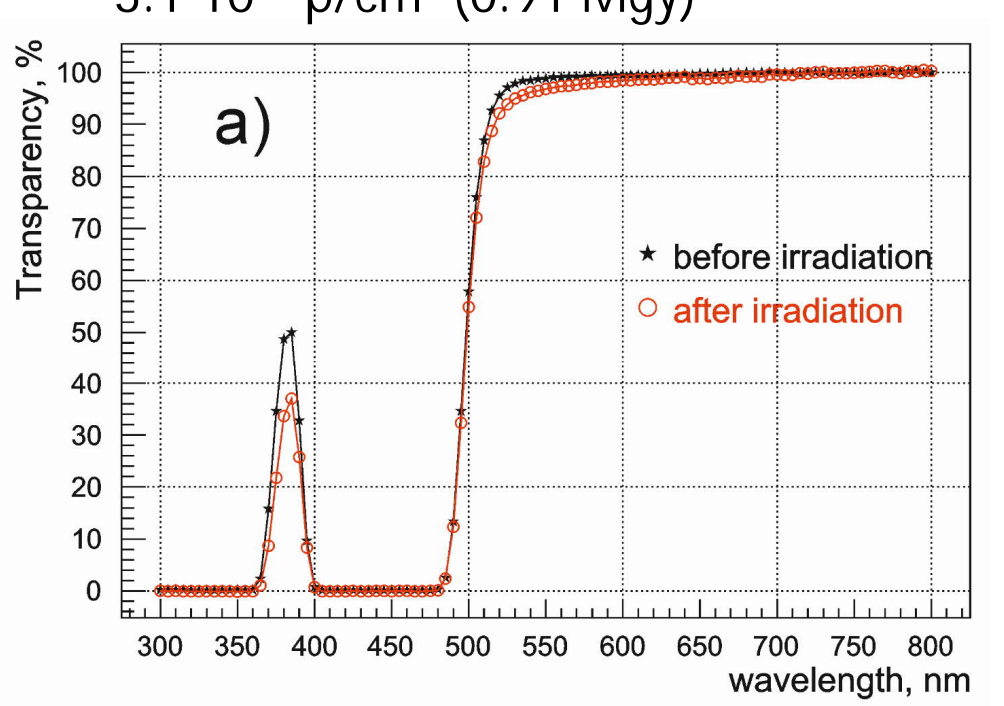

$\kappa=\frac{1}{d} \ln \frac{I_{\text {before }}}{I_{\text {after }}}=3.6 \mathrm{~m}^{-1}$ at $520 \mathrm{~nm}$ ( significantly better than LYSO)
Fiber irradiation , $24 \mathrm{GeV}$ protons $3.4 \cdot 10^{15} \mathbf{p} / \mathrm{cm}^{2}$ (1.02 M gy)

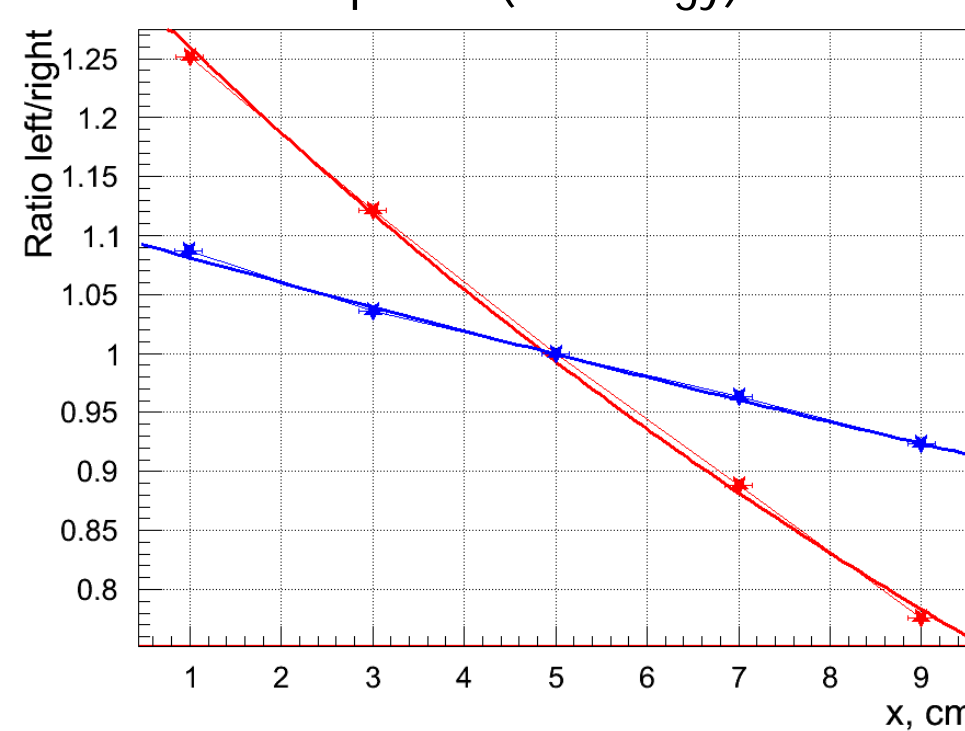

before irradiation: $L_{A T T}=101.5 \mathrm{~cm}$ after irradiation: $L_{A T}=33.6 \mathrm{~cm}$

$\rightarrow 0 K$ for $10 \mathrm{~cm}$ length after $1 \mathrm{M} \mathrm{Gy!}$ 


\section{timing properties: decay time}

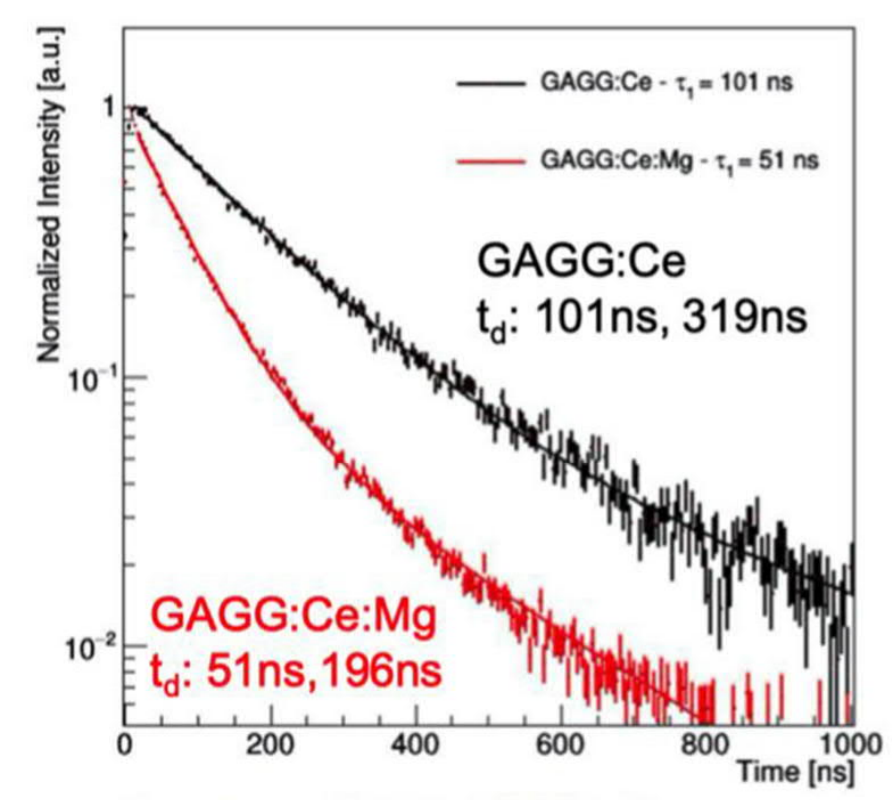

Kamada et al, 0-14-3 at SCINT2015

M. Lucchini et al, NIM A Volume 816 (2016), pp 176-183,

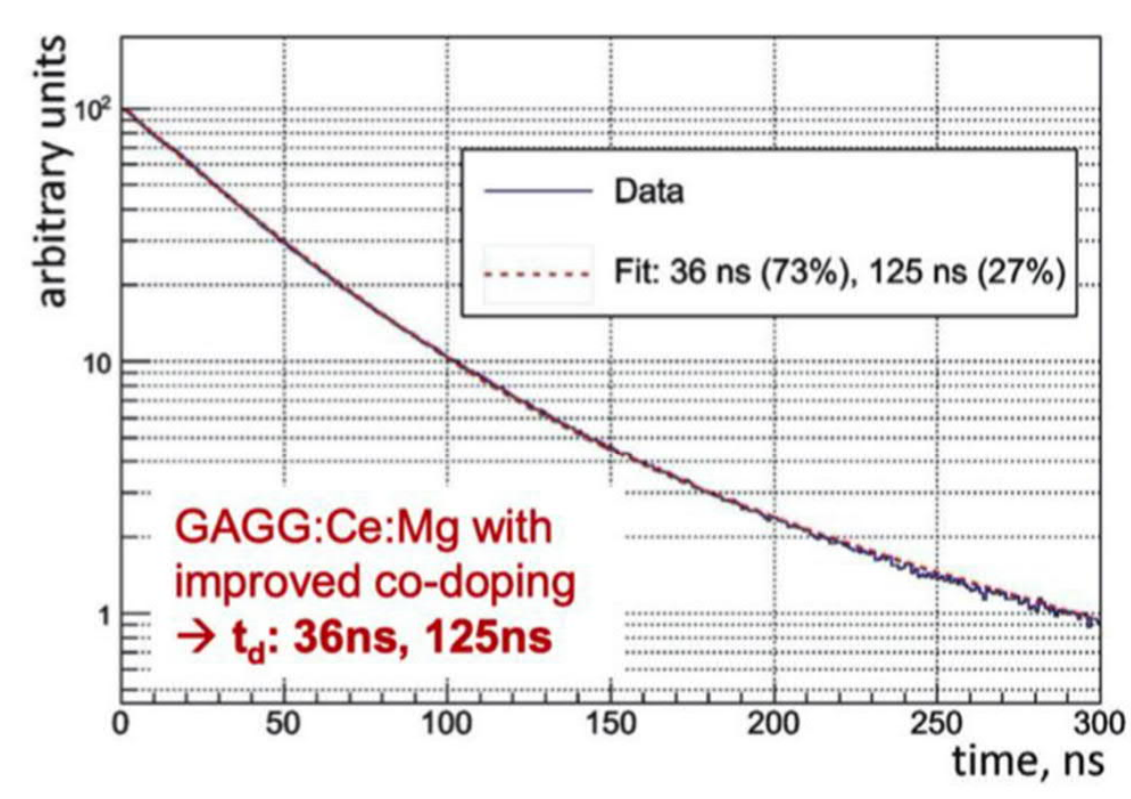

Nuclear Inst. and Methods in Physics Research, A 916 (2019) 226-229

it is important to minimize spill-over by minimizing pulse length ( $25 \mathrm{~ns} \mathrm{LHC} \mathrm{bunch} \mathrm{spacing)}$ co-doping with $\mathrm{Mg}, \mathrm{Ti}, \ldots$ reduces decay time and fraction of "long" exponential.

* Note the R\&D on the GAGG and GYAGG material (M . Korzhik, this conference; exhibition of FOM OS M aterials (M oscow)). 


\section{timing properties: rise time}
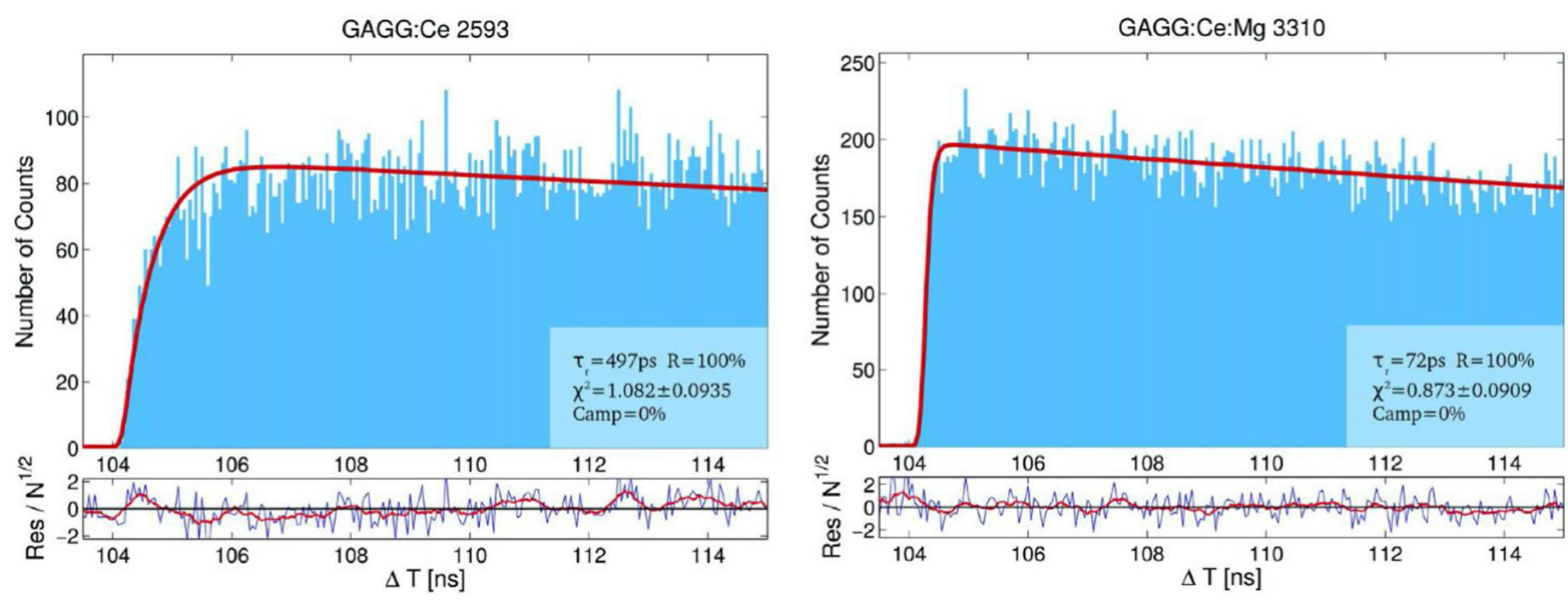

S.Gundacker, et al. NIM A 891 (2018) 42-52

The rise time is important for the precision of timing measurements co-doping with $\mathrm{Mg}$ also improves the rise time 


\section{Absorber for the central area}

- Should be more dense than Lead: hence Tungsten based

- should have a rather complicated shape to place crystal fibers

For the material, the options are pure W, W-Cu or W-Pb alloys

- pure W is very hard and brittle, difficult for machining

- W-Cu alloy is available on market, with good mechanical properties

- W-Pb alloy is preferable (smaller $X_{0}$ for same $R_{M}$ ), but is not commercially available

The R\&D on absorber technologies is ongoing (MISIS, Moscow). Several technologies are considered: Selective Laser M elting, Chemical Vapor Deposition, M etal Injection M olding

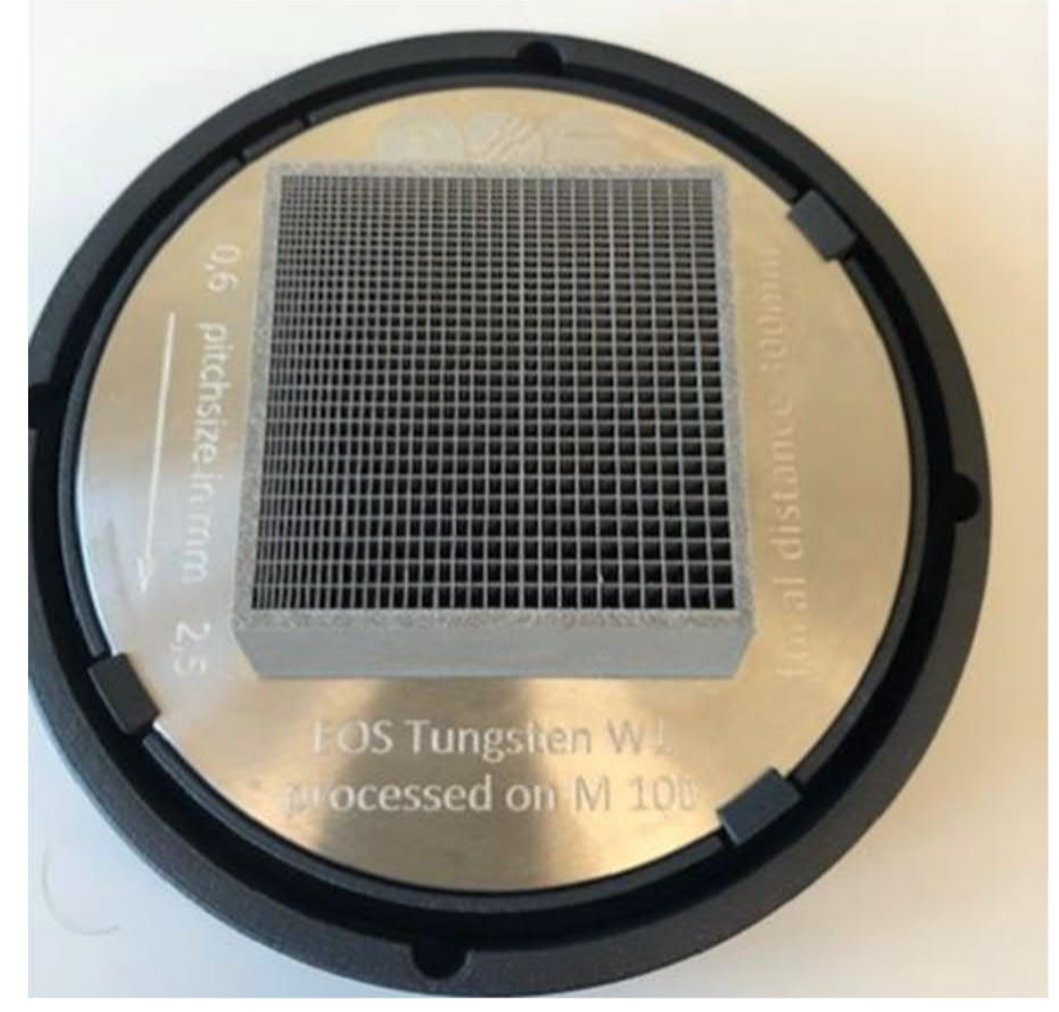
etc.

a sample produced by Selective Laser M elting, pure W (MISIS) 


\section{Prototype studies}




\section{Prototypes 2018}

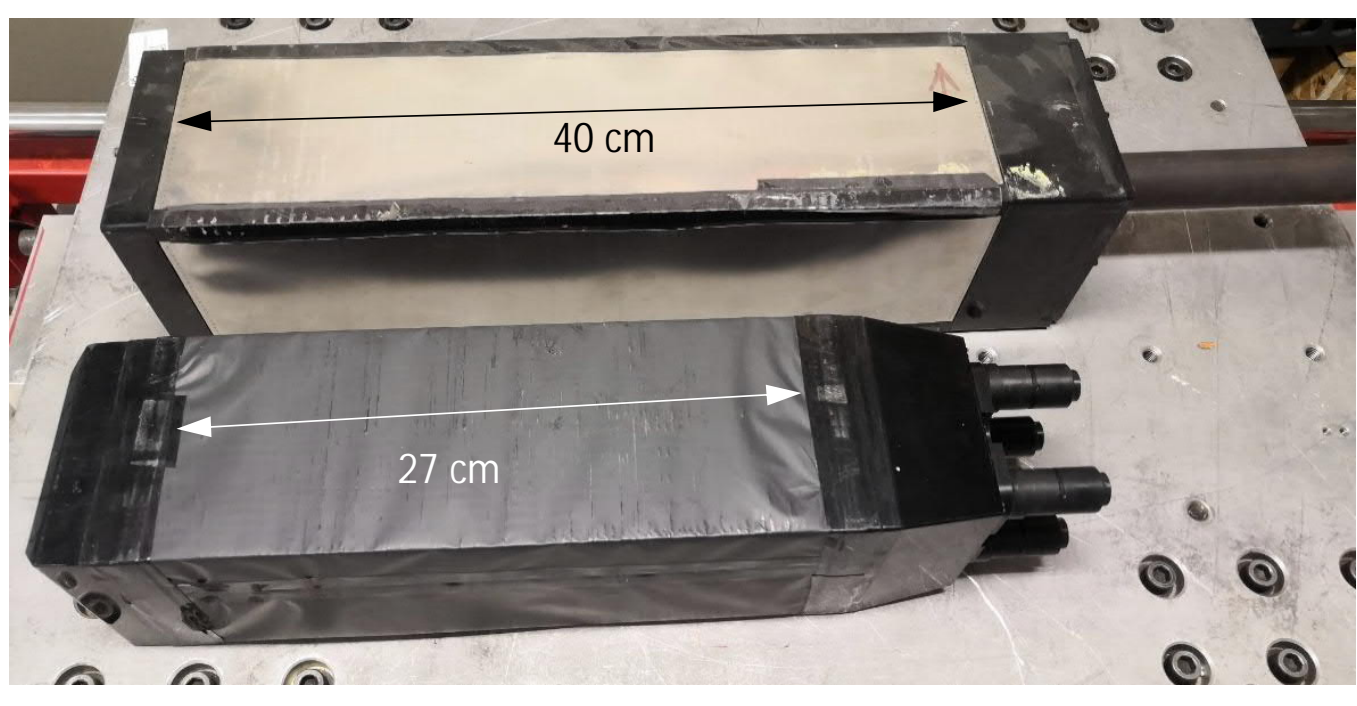

present ECAL module shashlik, $\mathrm{Pb}: \mathrm{Sc}=1: 2$ (vol) $25 \mathrm{X}_{0}=40 \mathrm{~cm} ; \mathrm{R}_{\mathrm{M}}=36 \mathrm{~mm}$

"short" shashlik module $\mathrm{Pb}: \mathrm{Sc}=1: 1$ (vol)

$25 \mathrm{X}_{0}=27 \mathrm{~cm} ; \mathrm{R}_{\mathrm{M}}=27 \mathrm{~mm}$ (produced in Protvino, 2017)

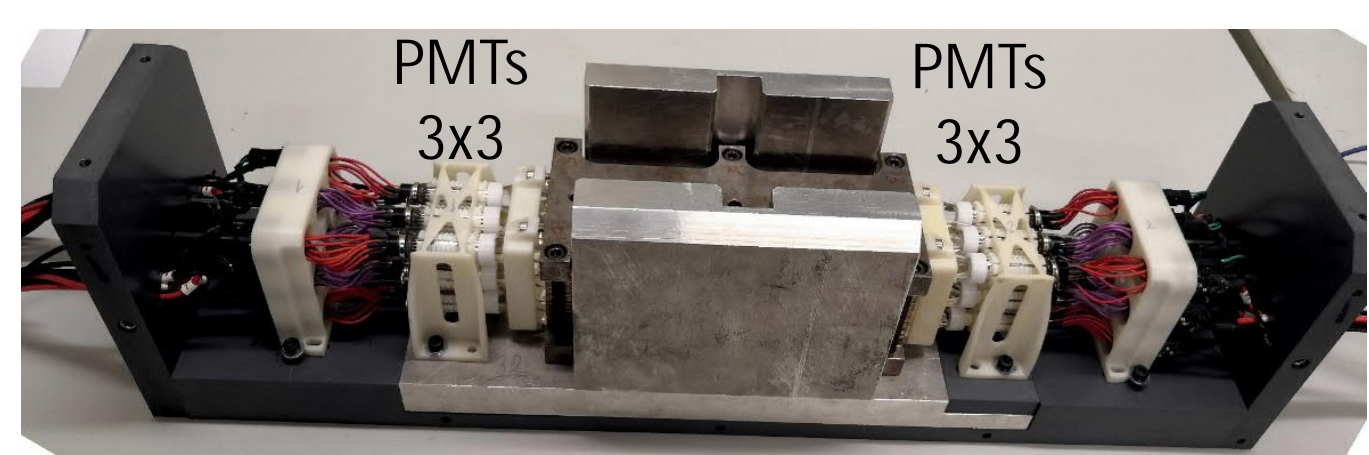

Cu-W alloy, $14.9 \mathrm{~g} / \mathrm{cm} 2$ $20 \mathrm{~cm}$ long module to reach $25 \times 0$ longitudinal segmentation: $10+10 \mathrm{~cm}$ 9 cells of $2 \times 2 \mathrm{~cm} 2$ with $M R \sim 1.5 \mathrm{~cm}$ 1 cell of GAGG, 4 cells of YAG, 4 cells of SCSF78 (KURARAY)

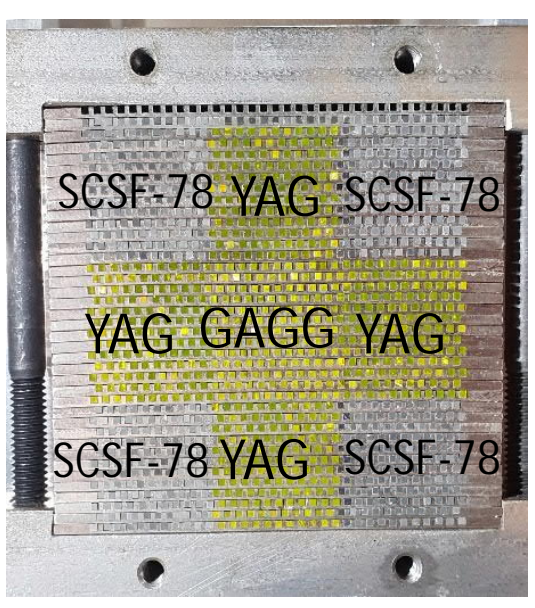




\section{beam test 2018}

- Energy resolution for SPACAL prototype

- time resolution for SPACAL and Shashlik

\section{Electronics:}

- LeCroy 1182 ADC for energy measurements

- CAEN DT5742 (5 GS/s, 12 bit) digitizer for time measurements

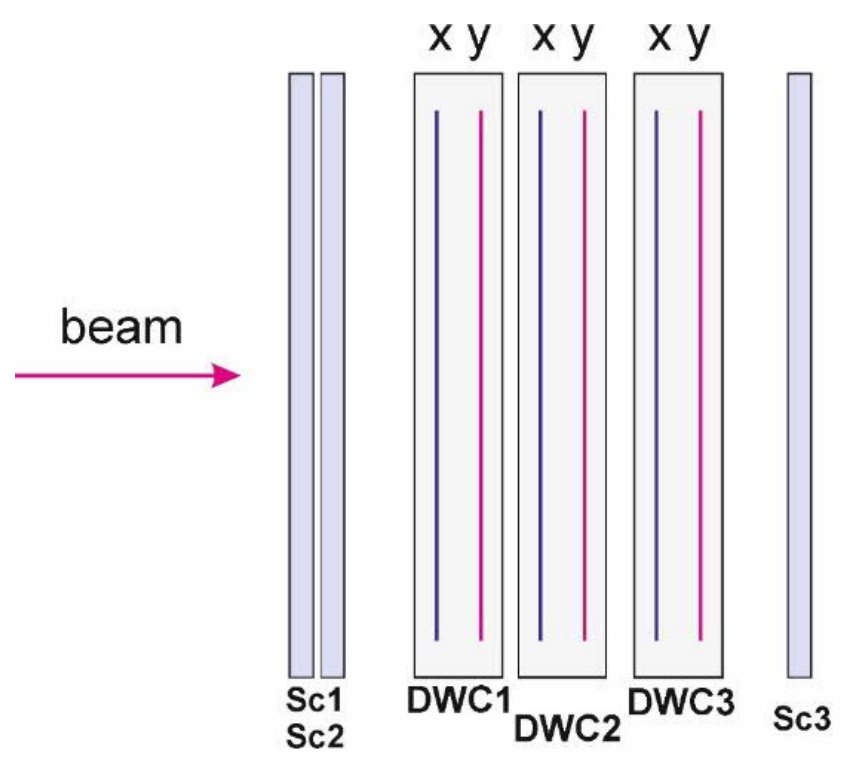

time reference:

2x MCP PMT with

$C$ radiator (plex)
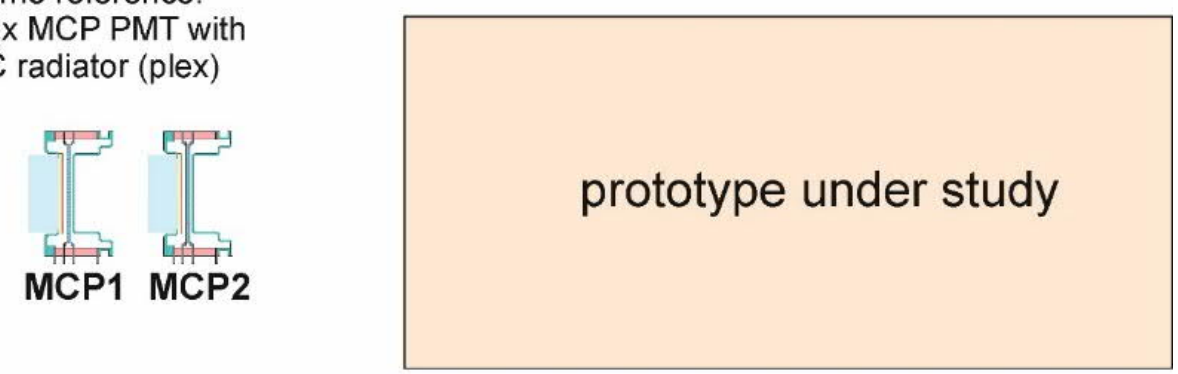

Time reference: two beam counters based on M CP PM Ts* ( $<20$ ps resolution)

DWC $=$ Delay Wire Chamber

(*) The MCP PMTs were kindly provided by Alexander and Mikhail Bamyakov, BINP, Novosibirsk 


\section{beam test 2018}
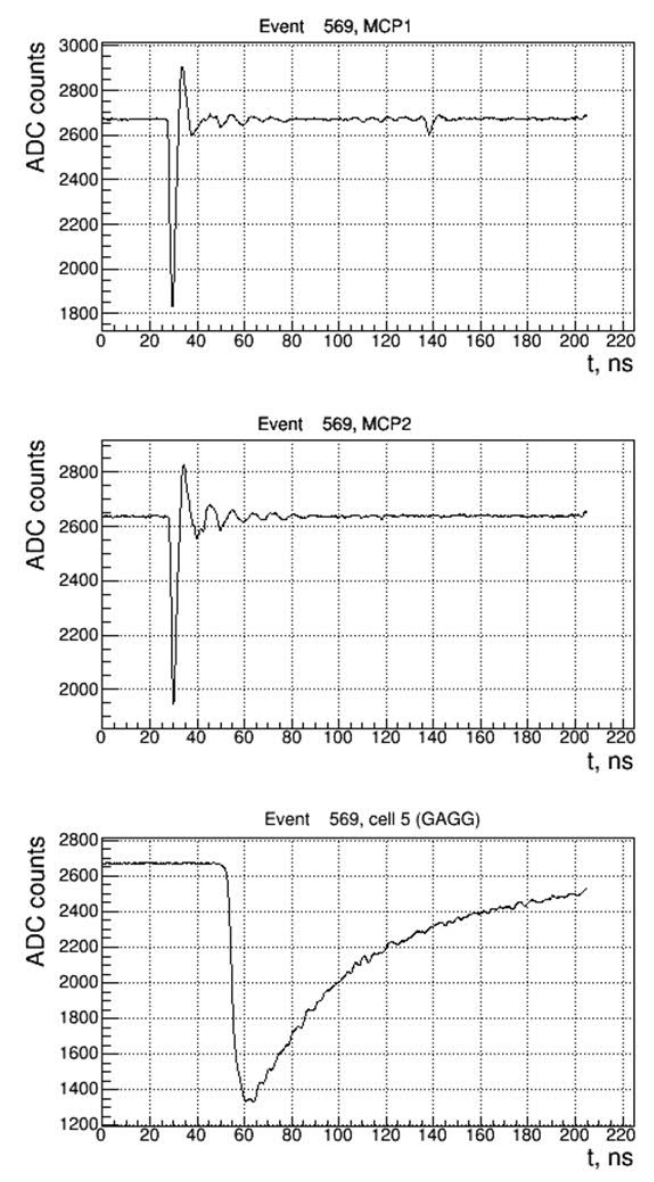

Time resolution in SPACAL, front section

\begin{tabular}{c|c|c}
$\mathrm{E}, \mathrm{GeV}$ & PMT HV & $\sigma(\mathrm{t}), \mathrm{ps}$ \\
\hline 20 & $630 \mathrm{~V}$ & 85 \\
\hline 20 & $730 \mathrm{~V}$ & 78 \\
\hline
\end{tabular}

Present ECAL module (Shashlik) + present PMT (R7899-20)

\begin{tabular}{c|c|c}
$\mathrm{E}, \mathrm{GeV}$ & PMTHV & $\sigma(\mathrm{t}), \mathrm{ps}$ \\
\hline 20 & $800 \mathrm{~V}$ & 69 \\
\hline 30 & $800 \mathrm{~V}$ & 56 \\
\hline 30 & $750 \mathrm{~V}$ & 57 \\
\hline
\end{tabular}

more details in: DOI : 10.1109/TNS.2020.2975570
SPACAL energy resolution

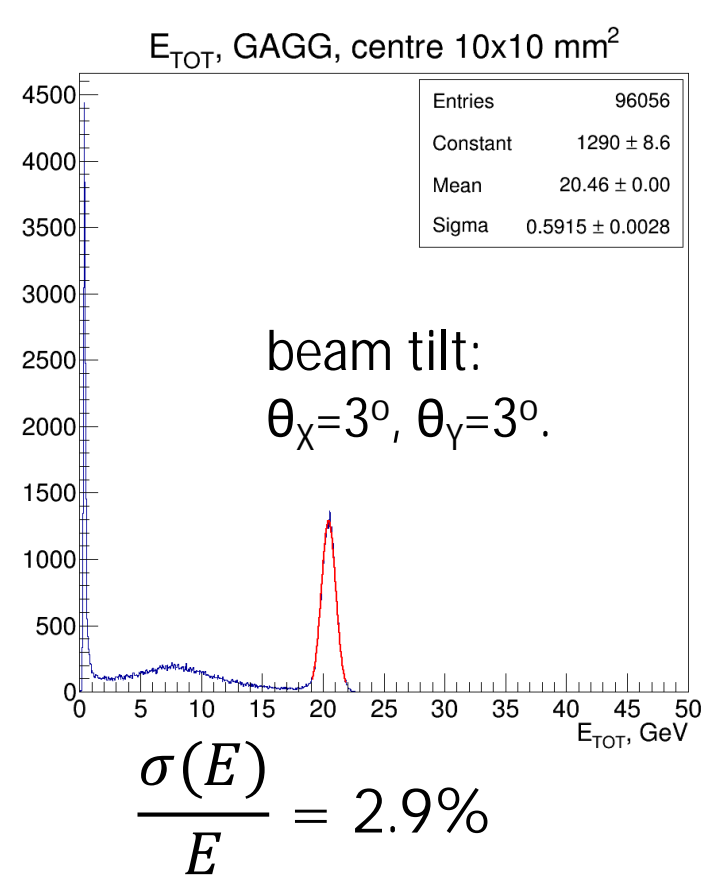

(3.1\% from GEANT4 simulation) 


\section{Prototypes 2019}

Longitudinally split versions of SPACAL and Shashlik (at 7X0 - shower max) improves time resolution;

also, creates a natural place for the separate timing layer
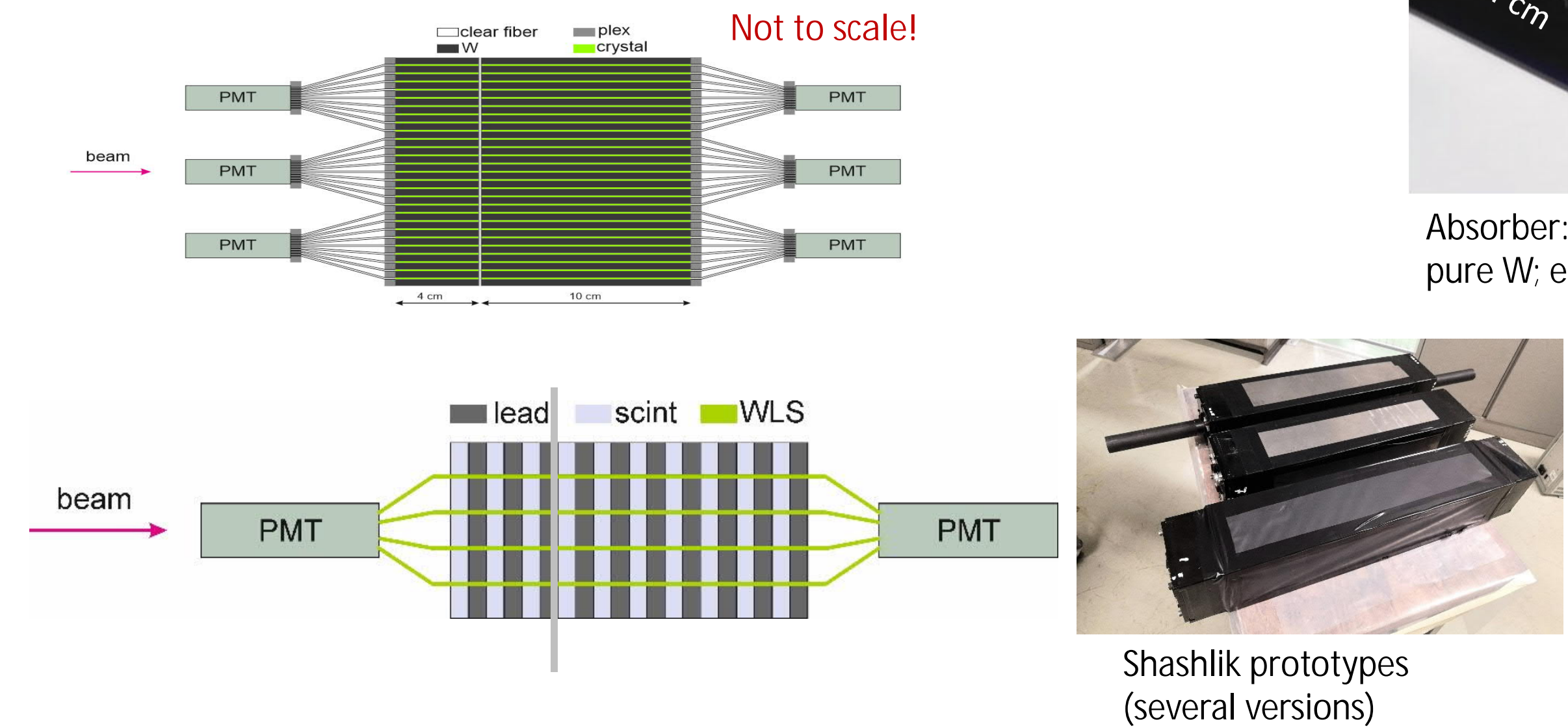

Scintillator:

YAG:Ce (Crytur), 6 cells

GAGG:Ce (FOM OS), 3 cells

Absorber: Crytur (CZ)

pure W; electroerosion cutting of $0.5 \mathrm{~mm}$ plates 


\section{Beam test 2019 (DESY)}

e+beam, energies 1-5 GeV

Basically same setup as in 2018

Shashlik with split WLS

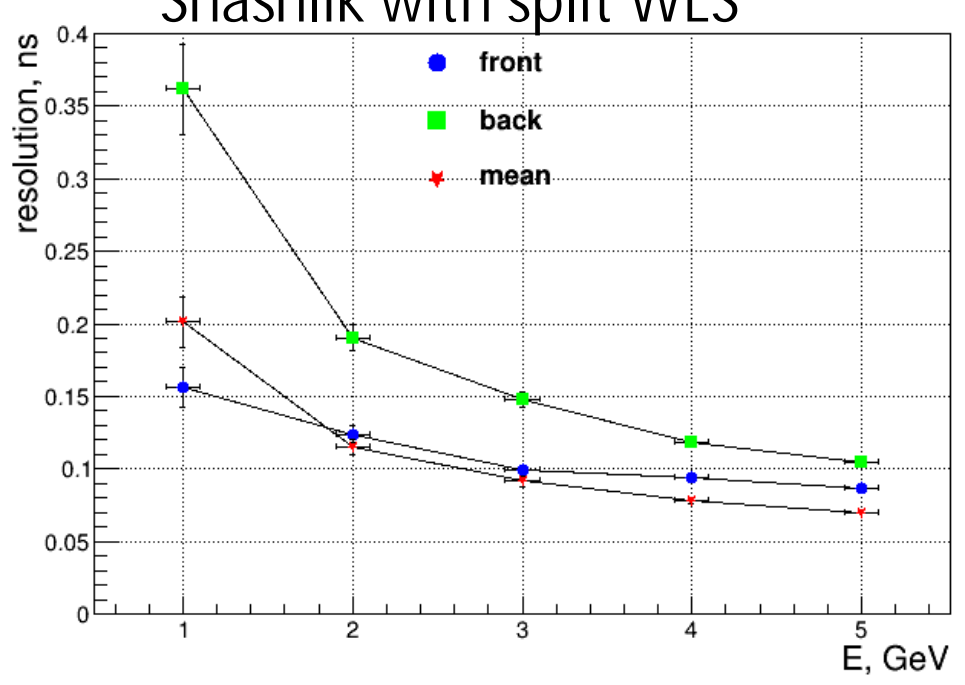

Better than the existing modules with standard readout: 70 ps resolution is achieved at $5 \mathrm{GeV}$ (same as @ $20 \mathrm{GeV}$ for the standard version)

Nearest plan: try new KURARAY WLS fibers YS-2

(much faster luminescence decay time than Y11)

$\rightarrow$ expect improvement in the time resolution

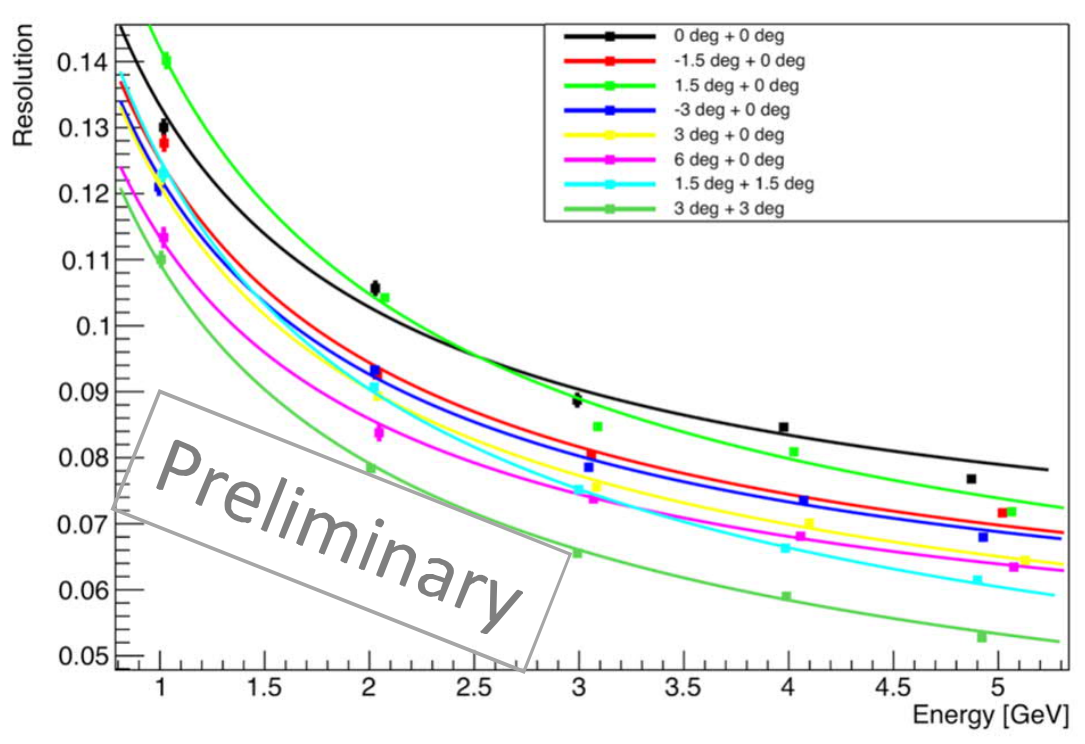

dependence of the energy resolution on incident angle (in agreement with GEANT4 simulation).

Stochastic term within 10-13\%, which is in the right ballpark.

The analysis is ongoing.

(Time resolution measurements for the SPACAL prototype failed, to be redone in $M$ ay 2020). ( 50 ps @ 5 GeV expected from simulation) 


\section{Conclusions}

- At present, LHCb is undergoing a major first upgrade. A second upgrade is foreseen in $\sim 2030$.

- The electromagnetic calorimeter needs some consolidation of the inner region by LHC LS3 (20252027) compatible with the running conditions after Upgrade II, which requires R\&D on radiation hard ECAL modules.

- In Long Shutdown 4 (LS4) a major upgrade of the ECAL will be required to cope with the increased luminosity, the harsh radiation and pile-up conditions, by replacing a significant part of the modules with new technologies.

- Generic R\&D and prototyping has started to develop radiation hard sampling ECAL modules of SPACAL type, as well as studies of intrinsic time resolution of ECAL modules. 